\title{
Numerical groyne layout optimisation for restoration projects in large rivers: An adaptive approach towards a desired morphodynamic equilibrium
}

\author{
Martin Glas ${ }^{1, *}$, Michael Tritthart ${ }^{2}$, Marcel Liedermann ${ }^{2}$, Sebastian Pessenlehner ${ }^{1}$, and \\ Helmut Habersack ${ }^{1}$ \\ ${ }^{1}$ Institute of Water Management, Hydrology and Hydraulic Engineering, Department of Water, \\ Atmosphere and Environment, BOKU—University of Natural Resources and Life Sciences Vienna, \\ Muthgasse 107, 1190 Vienna, Austria \\ ${ }^{2}$ Christian Doppler Laboratory for Sediment Research and Management, Institute of Water \\ Management, Hydrology and Hydraulic Engineering, Department of Water, Atmosphere and \\ Environment, BOKU—University of Natural Resources and Life Sciences Vienna, Muthgasse 107, \\ 1190 Vienna, Austria
}

\begin{abstract}
Integrative restoration measures at large rivers target the improvement of morphological and ecological conditions, under consideration of economic demands, specifically navigational ones. Alternative groyne layouts with e.g. reduced groyne spacing and lowered crest elevation reduce ecological deficits and have the potential to cease frequently encountered river bed incision of heavily modified rivers. On the other hand, the induced change in the morphodynamic equilibrium may interfere with navigation by reducing the water depth in the fairway. In 2009, a pilot project was realised on the Austrian Danube, including an alternative groyne layout. As a consequence the desired aggradations in the fairway became too large, leading to an increased dredging effort. In 2014, a numerical groyne optimisation, specifically a 3D numerical model in combination with a sediment transport model, was applied. In 2015, after implementing the optimised groyne layout in the field, morphodynamic equilibrium was reached reducing the need of extensive dredging. This equilibrium could be shown by analysing subsequently observed bathymetries until 2017. Moreover, the morphodynamic changes due to the groyne optimisation in 2015 were reproduced successfully with the numerical models. Thus they represent a cost effective tool for planning and optimising future restoration measures in large and heavily modified rivers.
\end{abstract}

\section{Introduction}

River restoration measures including geometrical changes (e.g. changes of groynes or guiding walls) influence the hydrodynamics and thus the morphodynamic equilibrium

\footnotetext{
${ }^{*}$ Corresponding author: martin.glas@boku.ac.at
} 
within a river. Ecological and economical demands (e.g. habitat quality, flood protection, navigation) on rivers are affected by those measures (e.g. [1, 2, 3]). Therefore numerical modelling tools and/or monitoring programmes in the field are widely used for assessing impacts and/or efficiency of restoration measures [4, 5]. Most studies on groynes and similar structures focus on the processes in and around the groyne fields [6, 7] as well as between the groyne field and the main channel [8]. Alauddin and Tsujimoto [9] were among the first investigating the influence of groynes on the evolution of hydrodynamics and sediment transport in the main channel numerically. A more detailed numerical study with regard to the main channel was conducted by [10]. Those studies with the focus on the main channel represent a useful approach to balance between ecological and economical demands, especially navigational ones.

Whereas numerical models provide the advantage of conducting predictions of hydrodynamics and sediment transport, a subsequent monitoring of morphology and hydrodynamic parameters provides the basis for a detailed analysis of the highly non-linear processes and influences in a river as well as the basis for the validation of the numerical tools.

This study aims at the assessment of a previously applied numerical and on-site groyne layout optimisation $[11,12]$ as well as the related numerical tools (hydrodynamic and sediment transport models). First, bed level changes will be analysed with the help of subsequent bathymetric measurements to evaluate the restoration success of the groyne layout optimisation. Finally, hydrodynamic and morphodynamic model results of the predicted variant will be validated with data obtained from the situation after the implementation of those groyne layout changes in the field.

\section{Study area}

The study site is located at a straight river reach (length of $3 \mathrm{~km}$ ) in the free flowing section of the Austrian Danube River east of Vienna (Fig. 1a) in proximity to the village Witzelsdorf. Heavy regulation works in the $19^{\text {th }}$ century for navigation and flood protection followed by a decrease of sediment supply due the construction of multiple reservoirs upstream in the 1970's have been coming along with a drastic river bed incision at a rate of 2 to $3 \mathrm{~cm}$ per year [13].

In 2008/2009 a pilot project (PP) was implemented at the study site including the aim to increase aggradation in the river bed (Fig. 1b). With the help of an innovative groyne layout and the removal of bank protections lateral erosion processes together with the wetted width were increased. Consequentially, water depth and bed load transport capacity decreased. Besides that, ecological improvements were targeted by increasing flow in the groyne fields and by installing a bypass flow along the shore with the help of lowered groyne roots.

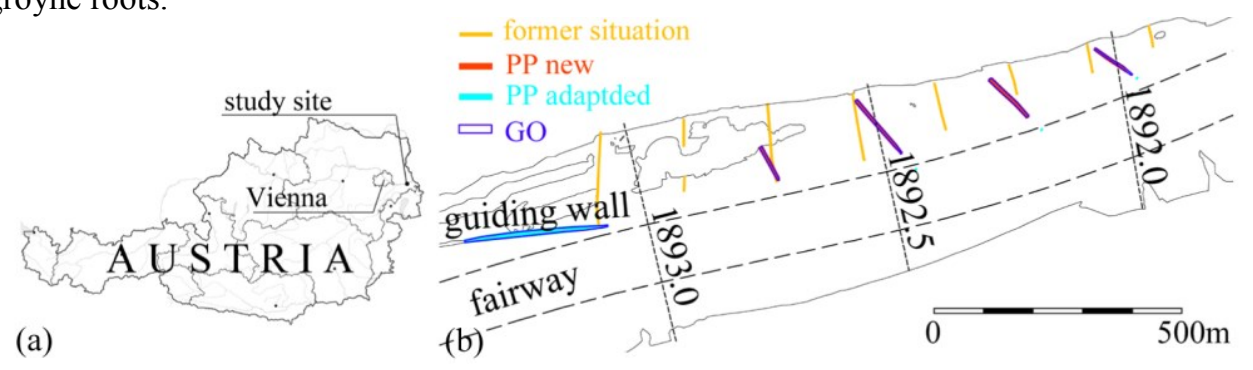

Fig 1. (a) Overview. (b) Sketch of the study site including the former groyne layout (2007), the adaptations during the PP (2008/2009) and the groyne layout optimisation GO (2016). Flow direction is from left to right. 
After implementation, monitoring and analysis of the PP, a further groyne layout optimisation (GO) was needed to be performed between 2014 and 2015. While river bed incision was stopped, the water depth in the fairway decreased, requiring recurrent and extensive dredging measures.

The hydrology of the study area is classified by the following characteristic discharges: low flow (RNQ; 94\% probability of exceedance) of $980 \mathrm{~m}^{3} \mathrm{~s}^{-1}$, mean flow (MQ) of $1930 \mathrm{~m}^{3} \mathrm{~s}^{-1}$ and highest navigable flow (HSQ; $1 \%$ probability of exceedance) of $5130 \mathrm{~m}^{3} \mathrm{~s}^{-1}$. Mean bed slope of the river stretch is 0.0004 and mean bankfull width is $402 \mathrm{~m}$. The grain size diameter is characterised by $\mathrm{d}_{\mathrm{m}}=25.1 \mathrm{~mm}$ and $\mathrm{d}_{90}=52.2 \mathrm{~mm}$.

\section{Geometrical changes}

In the scope of the PP (2008/2009), the former orthogonal groyne layout with a spacing of one times the average groyne length was changed to an attracting one with a spacing of two times the average groyne length (Fig. 2a, Fig. 1b). The crest elevation was reduced from approximately mean water level to a level $0.3 \mathrm{~m}$ above low water level (Fig. 2b). The crest elevation of the guiding wall upstream the groyne field was reduced from mean water level to a level $0.5 \mathrm{~m}$ above low water table. As a consequence, the wetted width $\mathrm{B}$ was increased by approximately 50 to $100 \mathrm{~m}$ for MQ and approximately $50 \mathrm{~m}$ for RNQ. Thus, the increased wetted width $\mathrm{B}$ indicated a river widening effect due to the groyne layout modification.

In the framework of the optimisation (GO; from 2014 to 2015) of the pilot project, 22 specific variants and combinations of variants of groyne layouts (and a guiding wall upstream of the groyne field) were investigated numerically in terms of reaching a desired morphodynamic equilibrium $[11,12]$. As an outcome of this numerical GO process, the crest elevation was increased by $0.65 \mathrm{~m}$ and $0.4 \mathrm{~m}$ (Fig. 1b) for the two upstream and the two downstream groynes, respectively, as crest elevation was found to be the most sensitive groyne parameter [10]. Additionally, the length of the groyne at the downstream end was increased by $20 \%$ (Fig. 2c, Fig. 1b) and the crest elevation of the guiding wall was increased by $0.5 \mathrm{~m}$. The outcome of the numerical GO was implemented in the field in October 2015.
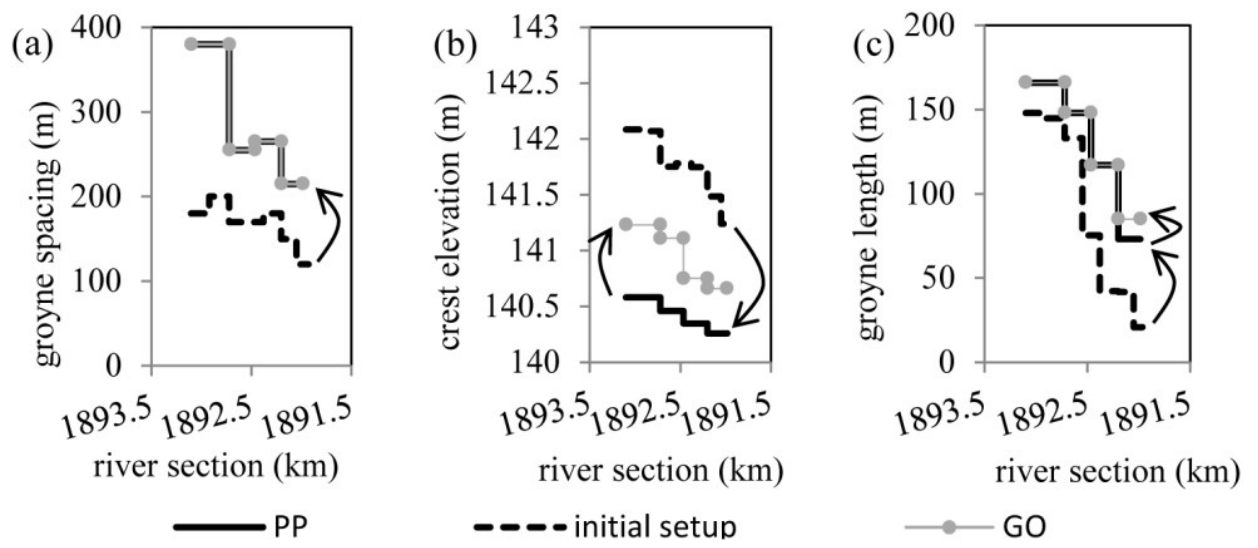

Fig. 2. Geometrical changes of the groyne layout during the project phases indicated by the groyne parameters (a) groyne spacing, (b) crest elevation and (c) groyne length. Flow direction is from left to right. 


\section{Models}

Digital elevation models (DEM) for each state of project were obtained from airborne laser scans combined with single- or multi-beam bathymetry measurements, provided by viadonau (Austrian Waterway Authority). Hydrodynamics were calculated with the 3D numerical model RSim-3D [14], which solves the Reynolds-averaged Navier-Stokes equations on an unstructured polyhedral computational mesh using the finite volume method. The average horizontal mesh distance was set between $1.5 \mathrm{~m}$ and $20 \mathrm{~m}$. The vertical mesh distribution was represented by six equally distributed layers over the flow depth. The computation mesh was extended by $500 \mathrm{~m}$ to $700 \mathrm{~m}$ up- and downstream the investigated river stretch to avoid disturbances from in- and outflow boundaries. Turbulence closure was provided by the standard k- $\varepsilon$ model [15]. Details on the hydrodynamic model are given in [16].

Sediment transport and morphodynamics were calculated with the numerical sediment transport model iSed $[17,18]$. The model considers both bedload and suspended sediment transport. A modified version of the equation from Meyer-Peter and Müller [19] considers non-uniform transport by means of a hiding-exposure correction introduced by [17]. Suspended sediment is calculated by a 2-dimensional convection-diffusion equation. An exchange term considers interaction with the river bed. Furthermore, river bed evolution over time is described by a sediment continuity equation and grain sorting is included by an exchange layer concept with mixing processes taking place in the top layer. Details of the sediment transport model are given in $[17,18]$.

Numerical model runs of this study were conducted for mean flow conditions $\left(\mathrm{MQ}=1930 \mathrm{~m}^{3} / \mathrm{s}\right)$ as the geometrical changes showed highest sensitivity on the hydrodynamic and morphodynamic changes [10]. A simulation time of one month was used for the calculation of bed level changes with the sediment transport model. Details on the model setup and calibration are provided in [10].

\section{Results and Discussion}

\subsection{Morphology}

In 2008/2009, mean aggradations of $+15 \mathrm{~cm}$ (Fig. 3b) — referred to the bed levels in 2001occurred within the study site (lowest common extent of all multi-beam measures) immediately after the implementation of the PP, whereas the whole Danube River between the cities Vienna and Bratislava indicated ongoing river bed degradation. In October 2013, those aggradations in the study area increased to a maximum value of mean aggradations of $0.42 \mathrm{~m}$, despite ongoing dredging measures for navigation (equivalent to $-0.38 \mathrm{~m}$ mean bed elevation changes). Those aggradations were partially triggered by a higher sediment input due to the remobilisation of fine sediments in the upstream chain of reservoirs during extreme flood events ( $\gg$ HSQ; Fig. 3a) [20]. Especially, the extreme flood in 2013 $\left(\mathrm{Q}=10,460 \mathrm{~m}^{3} \mathrm{~s}^{-1}\right)$ - in combination with the adapted groynes within the $\mathrm{PP}$-led to the requirement for expensive dredging measures and thus the initiation of the GO project. Without dredging measures in 2014 and 2015 mean bed levels would have been higher by $+0.19 \mathrm{~m}$. After the implementation of the GO the mean bed levels reduced to a value of $+10 \mathrm{~cm}$ referred to the bed levels from 2001 .

Figure 4 shows that the change of mean bed levels occurs in the whole stretch within the fairway. Maximum aggradations in the fairway due to the PP were up to $+1.5 \mathrm{~m}$ (Fig. $4 \mathrm{a})$, reducing the water depth in the fairway. As a consequence of the application of the 

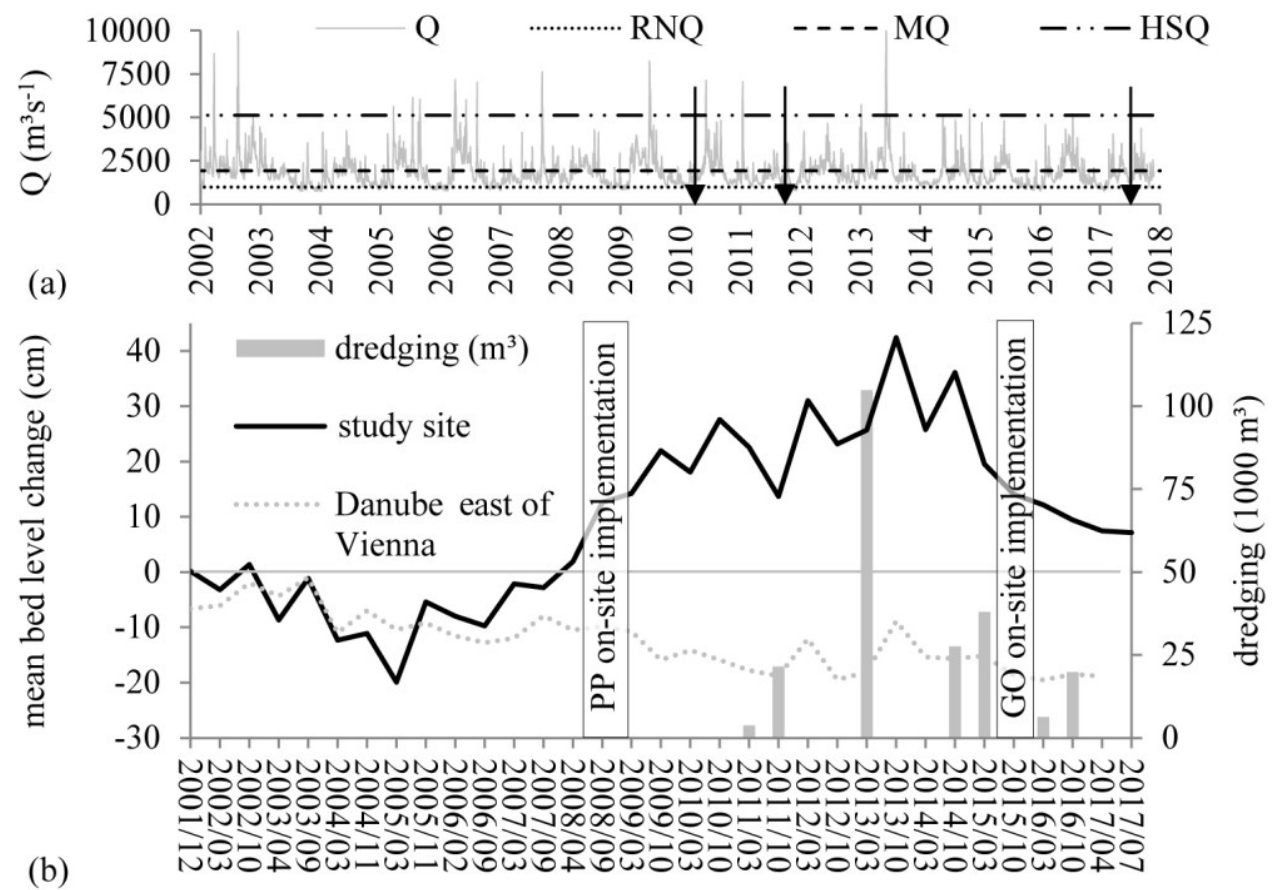

Fig. 3. (a) The hydrograph is shown in comparison to the characteristic discharges of the Danube River. Arrows show considered numerical models. (b) The mean bed level changes over time in relation to 2001/01 for the study site and the complete river stretch between the cities of Vienna and Hainburg (river km 1920.00 to 1872.00) are illustrated. Dredging volumes at the study area are indicated with bars.

GO, maximum erosions due to the GO showed values up to $-1.0 \mathrm{~m}$ (Fig. $4 \mathrm{~b}$ ). In terms of the efficiency of the GO, the water depth in the fairway was increased to avoid extensive dredging for navigational purposes and the ongoing river bed incision was stopped in this river reach. Determining possible effects of extreme flood events ( $\gg$ HSQ) on bed level change with respect to the GO needs further monitoring and numerical modelling.

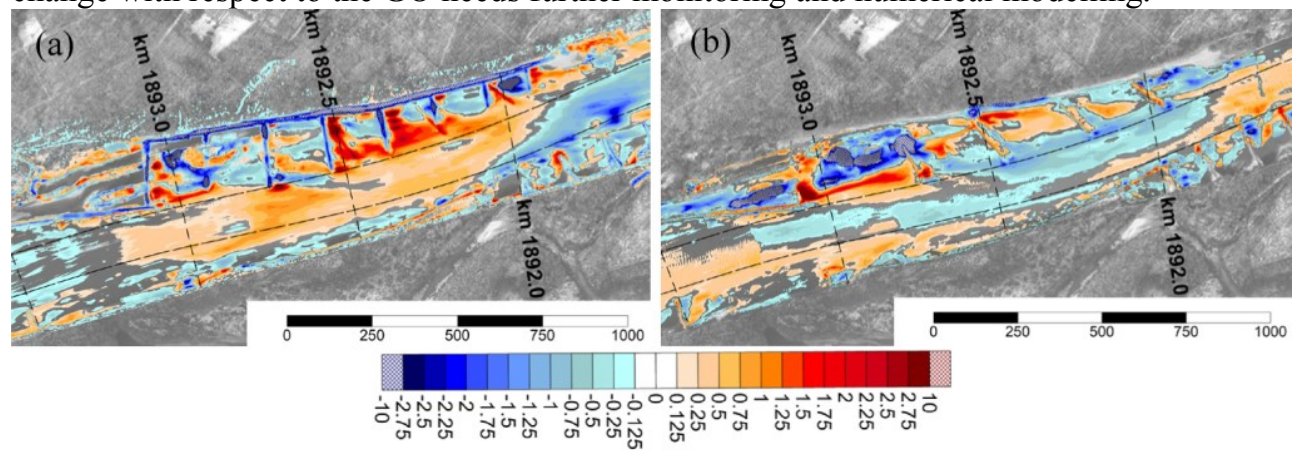

Fig. 4. Bed level difference between (a) 2011/10 (post pilot project/pre optimisation) and 2007/10 (pre pilot project) and between (b) 2017/03 (post optimisation) and 2011/10 (post pilot project/ pre optimisation) 


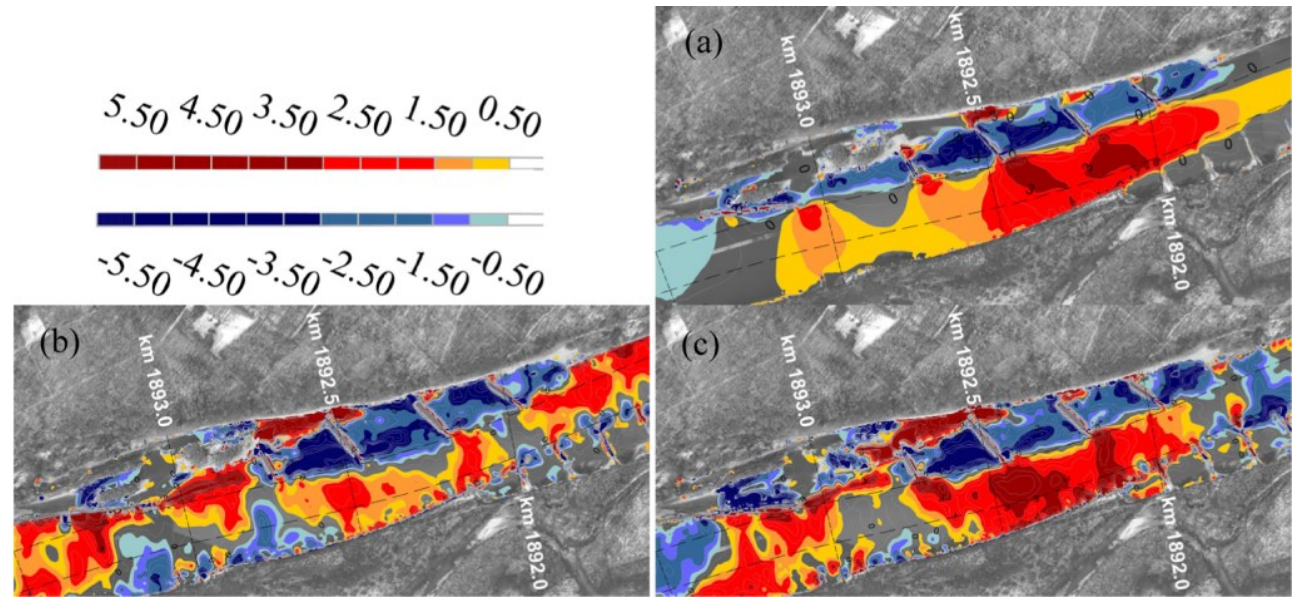

Fig. 5. (a) Modelled prediction $[11,12]$ of changes in bed shear stress $\left(\mathrm{N} \mathrm{m}^{-2}\right)$ due to the numerical GO using initial bed levels from 2010/02; (b) modelled differences in bed shear stress due to the implemented GO (initial bed levels from 2017/07) in comparison to 2011/10; (c) modelled differences in bed shear stress due to the implemented GO (initial bed levels from 2017/07) in comparison to $2010 / 02$. Flow direction is from left to right.

\subsection{Hydrodynamics}

In 2014, the scenario based modelling during the GO $[11,12]$ led to the prediction of an increase of bed shear stress in the fairway up to $+3.5 \mathrm{Nm}^{-2}$ (Fig. 5a). In 2017, after the implementation of the GO in the field, the numerical models were updated with the bed levels from 2017/06. Figure 5b, c show that the pattern of the changes in bed shear stress due to the implemented GO were approximately similar to the a-priori numerically predicted changes (Fig. 5a), when compared to the numerical models from 2011/10 or $2010 / 02$. This accordance supports the validity of the applied numerical models in order to assess river restoration measures.

On the other hand, the predicted changes in the water table elevation for the numerical $\mathrm{GO}$ - water table rises in the upper section of the groyne field and the section upstream the groyne field - were not observed after the implementation of the GO, as the bed levels in this area were substantially lower (up to $0.5 \mathrm{~m}$, Fig. 4b) in $2017 / 07$ than in $2010 / 02$ or $2011 / 10$. In contrast, from $2010 / 02$ to $2017 / 07$, modelled water depth increased by up to $0.5 \mathrm{~m}$, which, in total, supported the validity of numerically predicted bed shear stress changes. As found for another reach of the Danube River further downstream [21], the sensitivity of the initial river bed (e.g. high and low scenario of the initial river bed) had to be considered for the numerical prediction to reach a more precise agreement for future assessments.

\subsection{Sediment transport}

Analogous to the bed shear stress predictions, sediment transport and morphodynamics were compared between the predictions before the GO implementation $[11,12]$ and the updated model results after the GO implementation by considering mean flow and a simulation time of one month. Thereby, the pattern of predicted differences $[11,12]$ of modelled bed level changes in the fairway (initial bed levels from 2010/02) due to the GO (Fig. 6a) were similar to the differences of the updated sediment transport model including hydrodynamics and initial bed levels from 2017/10 (Fig. 6b). The magnitude of bed level 


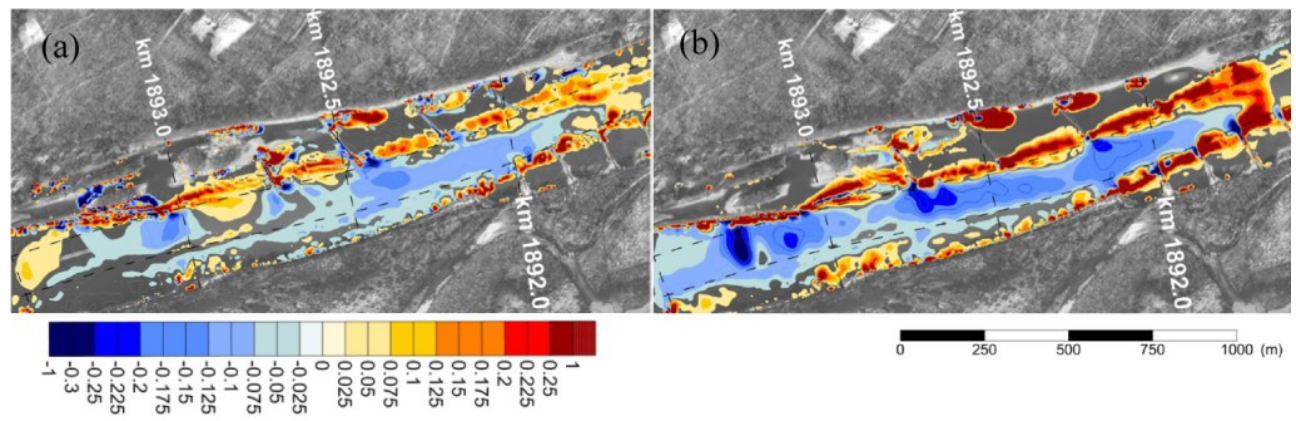

Fig. 6. (a) Modelled prediction $[11,12]$ of differences in bed level changes (m) after 1 month of mean flow conditions due to GO (initial DEMs from 2010/02); (b) Modelled differences in bed level changes $(\mathrm{m})$ after 1 month of mean flow conditions due to the implemented GO derived by comparing models with an initial DEM from 2017/03 and an initial DEM from 2010/02. Flow direction is from left to right.

changes was slightly higher for the updated model. However, the approximate accordance of the tendency of relative erosions supports the validity and future usability of the models and the model setup. Higher accordance is expected to be reached by implementing long term morphodynamic models covering the whole period between 2010 and 2017. Until now, such models were not applied due to the huge computational effort. Moreover, as mentioned in section 5.1, possible effects of extreme floods on the prediction of bed levels due to groyne optimisation needs future attention.

\section{Conclusions}

In this study, a restoration measure (PP) and a following groyne layout optimisation (GO) were assessed with the help of subsequent bathymetric surveys and numerical models. Desired aggradations occurred after the implementation of the PP helping to cease river bed incision. On the other hand, the reduced water depth in the fairway due to exaggerated aggradations led to the requirement for dredging measures after implementation of the PP and to the need for an adaptive optimisation process (GO). The aggradations were triggered by both increased sediment input from the upstream reservoir chain and reduced sediment transport rates due to geometrical changes of groynes in the study area. Aggradations were on a maximum right after an extreme flood event $(+0.40 \mathrm{~cm}$ mean bed level rise in the fairway). By the implementation of the GO, the morphodynamic equilibrium was changed to an elevation which, on the one hand, ceased extensive dredging measures and which, on the other hand, stopped river bed degradation in this particular river reach. Besides that, so far no extreme flood events occurred after the GO, which was found to be an important part for future monitoring.

In the second part of this study, it was found that changes in bed shear stress and bed level differences were predicted successfully during the numerical GO process. However, long term morphodynamic modelling was not applied, effecting the capability towards a more accurate prediction of changes in bed levels (initial bed levels for the models before and after the implementation of the GO differed substantially in this study), and thus, water depth and water levels. Future modelling tools should therefore focus on the improvement of the computational performance to enable such long-term simulations in combination with three-dimensional RANS models. Until reaching those substantial improvements, the applied approach provides a useful approximation to assess restoration measures at large rivers. 
The financial support by the Austrian Federal Ministry for Digital, Business and Enterprise and the National Foundation for Research, Technology and Development is gratefully acknowledged. Parts of this work have been funded by the EU project DREAM SK-AT (Interreg V-A Slovakia - Austria). Furthermore, we thank the Austrian Waterway Authority viadonau and the Austrian Ministry for Transport, Innovation and Technology for providing bathymetry data and additional support.

\section{References}

1. A. W. Lorenz, S. Stoll, A. Sundermann, P. Haase, Ecological Engineering 61 (2013)

2. P.H. Nienhuis, R.S.E.W. Leuven, Hydrobiologia 444 (2001)

3. G. Akkerman, M. Van Heereveld, H. Barneveld, R. Smedes, Proceedings of the International Conference on Fluvial Hydraulics - River Flow (2006)

4. E. Formann, H. Habersack, S. Schober, Geomorphology 90 (2007)

5. M. Liedermann, P. Gmeiner, A. Kreisler, M. Tritthart, H. Habersack, Earth. Surf. Proc. Land. 43, 2 (2017)

6. S. Ouillon, D. Dartus, J. Hydraul. Eng-ASCE 123, 11 (1997)

7. A. Sukhodolov. J. Hydraul. Res. 52, 1 (2014)

8. M. F. M. Yossef, H. J. de Vriend. J. Hydraul. Eng-ASCE 137, 5 (2011)

9. M. Alauddin, T. Tsujimoto, Int. J. Sediment Res. 27, 2, (2012)

10. M. Glas, K. Glock, M. Tritthart, M. Liedermann, H. Habersack, J. Hydraul. Res., (in press)

11. M. Tritthart, M. Glas, M. Liedermann, H. Habersack, Herausforderung Sedimenttransport - Methoden und Konzepte im Flussbau, Karlsruhe: Bundesanstalt für Wasserbau (BAW) (2014)

12. H. Habersack, M. Glas, P. Gmeiner, M. Klösch, M. Liedermann, M. Tritthart, Optimierung der Niederwasserregulierung (Variation der Buhnenparameter), Project report (2014)

13. H. Habersack, M. Liedermann, M. Tritthart, Proceedings of the 6th International Symposium on Ecohydraulics, Christchurch, New Zealand (2007)

14. M. Tritthart, Wiener Mitteilungen, Wasser-Abwasser-Gewässer 193 (2005)

15. B. E. Launder, D. B. Spalding, Comput. Methods. Appl. Mech. Eng. 3, 2, (1974)

16. M. Tritthart, D. Gutknecht, Eng. Appl. Comp. Fluid. 1 (2007)

17. M. Tritthart, B. Schober, H. Habersack. J. Hydraul. Res. 49, 3, 325-334 (2011)

18. M. Tritthart, B. Schober, H. Habersack. J. Hydraul. Res. 49, 3, 335-344 (2011)

19. E. Meyer-Peter, R. Müller, Proceedings of the 2nd IAHR Congress, Stockholm, Sweden (1948)

20. M. Haimann, J. Aigner, P. Gmeiner, P. Lalk, H. Habersack, Österr. Wasser- und Abfallw. 70, 1-2 (2017)

21. M. Tritthart, M. Glas, M. Liedermann, H. Habersack, Proceedings of the 12th International Conference on Hydroscience \& Engineering, Tainan, Taiwan (2016) 